\title{
Marguerite de Coüasnon, Écrire de soi. Madame de Genlis et Isabelle de Charrière, l'autorité féminine en fictions (1793-1804)
}

\section{Paola Perazzolo}

\section{(2) OpenEdition \\ Journals}

Edizione digitale

URL: https://journals.openedition.org/studifrancesi/1352

DOI: 10.4000/studifrancesi. 1352

ISSN: 2421-5856

\section{Editore}

Rosenberg \& Sellier

\section{Edizione cartacea}

Data di pubblicazione: 1 décembre 2015

Paginazione: 594

ISSN: 0039-2944

\section{Notizia bibliografica digitale}

Paola Perazzolo, «Marguerite de Coüasnon, Écrire de soi. Madame de Genlis et Isabelle de Charrière, l'autorité féminine en fictions (1793-1804)», Studi Francesi [Online], 177 (LIX | III) | 2015, online dal 01 décembre 2015, consultato il 21 septembre 2021. URL: http://journals.openedition.org/studifrancesi/ 1352 ; DOI: https://doi.org/10.4000/studifrancesi. 1352

Questo documento è stato generato automaticamente il 21 septembre 2021.

\section{cc) (†) $\odot$}

Studi Francesi è distribuita con Licenza Creative Commons Attribuzione - Non commerciale - Non opere derivate 4.0 Internazionale. 


\title{
Marguerite de Coüasnon, Écrire de soi. Madame de Genlis et Isabelle de Charrière, l'autorité féminine en fictions (1793-1804)
}

\author{
Paola Perazzolo
}

\section{NOTIZIA}

MARGUERITE DE COÜASNON, Écrire de soi. Madame de Genlis et Isabelle de Charrière, l'autorité féminine en fictions (1793-1804), Rennes, PUR, 2013 («Interférences»), pp. 310.

Interessata alla scrittura femminile del diciottesimo secolo e alla ricezione di Rousseau, l'A. coniuga in questo volume tratto dalla sua tesi di dottorato i suoi due centri di ricerca. Coüasnon tratta infatti dell'opera di due illustri femmes de lettres mettendola in relazione con la figura del Ginevrino, accostamento necessario se si considera il periodo di produzione letteraria preso in esame: 1793-1804. Come sottolinea nella Préface Isabelle BROUARD-ARENS, si tratta infatti di un decennio difficile per delle scrittrici che si propongano di prendere posizione nei confronti di un'attualità radicale: in questo contesto storico-politico Isabelle de Charrière e Madame de Genlis dimostrano la loro originalità e audacia, riuscendo a proporre testi che si situano, con i dovuti distinguo, «parmi les œuvres engagées avec le paradoxe qui consiste à dépasser l'esprit partisan: être engagée par une écriture de la distance» (p. 8). In effetti, quelle che Brouard-Arens considera come «passeuses» culturali (p. 7) adottano una posizione intermedia tra $\mathrm{i}$ valori di un Ancien Régime ormai decaduto e gli ideali di un Nuovo Mondo in perenne divenire. Lo fanno reinterpretando il pensiero di Rousseau - pensatore all'epoca assurto a vero e proprio maitre à penser dei rivoluzionari - relativamente alla valorizzazione del ruolo femminile a livello individuale e collettivo e alla sua posizione nella società. Se le figure dell'emigrato e del paria si possono considerare come una metafora del destino 
delle femmes d'esprit dell'epoca, nella loro produzione Isabelle de Charrière e Madame de Genlis tratteggiano educatrici, madri e scrittrici che, come loro stesse, si pongono in contrasto con la doxa rivendicando, pur se a livello ideale, un ruolo femminile nuovo e attivo nella società rivoluzionaria. Secondo Marguerite Coüasnon, l'interesse dimostrato da queste autrici nei confronti di una Rivoluzione in fieri si concretizza nel tentativo di riconciliare gli estremi e di moderare le istanze più radicali, riprendendo e rivisitando il pensiero rousseauiano al fine di rimodellare l'immagine femminile "coniugalista», e di ipotizzare la possibilità femminile di un'affermazione individuale nello svolgimento di un ruolo importante a livello pedagogico e critico.

2 Basato soprattutto sull'analisi dei legami intertestuali tra Madame de Genlis e Isabelle de Charrière da un lato e il Ginevrino dall'altro, il presente volume contribuisce alla riflessione sulla ricezione postrivoluzionaria di quest'ultimo, ribadendo al contempo la modernità del pensiero e della scrittura di due autrici ancora ingiustamente sottovalutate. 